\title{
Comparative Performance Evaluation of Top Hammer Miller Machine to Crop Residue Crushing for Livestock Feed Purpose
}

\author{
Abayineh Awgichew \\ Oromia Agricultural Research Institute, Asella Agricultural Engineering Research Center \\ P.O. Box 06, Asella Ethiopia
}

\begin{abstract}
Crop residues are considered among the most important materials in Ethiopia especially maize stalk, bean stalk, sorghum stalk, and wheat and barley straw. There are many types and models of imported top hammer miller in Ethiopia to assist in milling the grain. Those machines which are imported have many problems such as size of mill and rusting of hammers which not advisable to human food. Therefore the machines adapted and evaluated for livestock feed process purpose in terms of crop residues like maize stalk, bean stalk and wheat straw with predetermined feed rate and hammers' shaft speed (RPM). The research was conducted at Asella Agricultural Engineering Research Center (AAERC), Maki and Bokoji district to evaluate the machine performance in crushing maize stalk, bean stalk, and wheat straw for animal feed. In this paper, two top feed hammer mills were used. They are collected from market and Bako Agricultural Engineering Research Center (BAERC). The performance of the machine is evaluated in terms of crushing capacity, crushing efficiency and crushing loss. The output of the market top hammer miller was satisfactory. The market top hammer miller produced a highest crushing efficiency and capacity about $99.33 \%$ and $152.54 \mathrm{~kg} / \mathrm{hr}$ while the BAERC's was produced $94 \%$ and $78.68 \mathrm{~kg} / \mathrm{hr}$, respectively. The crushing losses of the market top hammer miller were $2.67,0.67$ and $5 \%$ on maize stalk, bean stalk and wheat straw respectively.
\end{abstract}

Keywords: crushing capacity, crushing efficiency, crushing loss, RPM

DOI: $10.7176 / \mathrm{CPER} / 61-02$

Publication date: April $30^{\text {th }} 2019$

\section{INTRODUCTION}

Ethiopia has the largest livestock population in Africa (wiki, 2017, CSA, 2015/16). The livestock subsector comprised 11 percent of national GDP and 24 percent of agricultural GDP and is a source of revenue for $60-70$ percent of the population. Between 2005 and 2008, livestock population (in terms of cattle, sheep, and goats) in Ethiopia grew at 22 percent. Oromia region produced the largest share, 38 percent of livestock within Ethiopia, while Amhara and Southern Nations, Nationalities, and Peoples (SNNP) regions produced 26 and 16 percent of livestock shares, respectively according CSA, 2013

Livestock play a central role in the natural resource-based livelihood of the vast majority of the population living in developing countries. However, most of these regions face the problem of acute shortage of feed resources. The pastures are degraded and poorly managed and the area under green forage crops is shrinking due to increase in human population and urbanization (FAO, 2012).

In other hand, Agricultural farming is characteristics of huge scrap and waste material. On completion of harvesting activities, the biomass is invariable left in the fields to decay naturally or disposed of by burning away. However, a small part of the biomass is used as domestic fuel and cattle feed. Normally, farmers pay a great attention to collection of the widely scattered and strewn stem fragments in the field owing to high cost of labor as also that of transporting the stalk to the place where it store or consumption. In general, there is no alternative processing technology for farmers, that the agricultural crop residue can be put to productive use and products of significance.

On the national scene prospect, the quantity of biomass so generated is certainly very large. This underlines the undisputed need for effective end use this form of agricultural waste. Huge quantity of biomass in the form of stalk, if systematically collected and processed, can be gainfully deployed for produce animal feed.

\section{Problems of the Statement}

Livestock feed preparation is a great problem nowadays. Earlier time there is grazing area. But now the quest to increase the agricultural production in all surfaces, have intensified crop production by increasing cultivated areas causes reducing the grazing areas. Livestock farmers especially in the sector of goats, sheep and cattle are constantly faced with problem of feed shortage during the dry season. During this period, grazing livestock lose weight and in extreme cases some deaths do occur. As a result, bulky of feeds available for ruminants in these regions are the crop residues. The crop residues have low nutritional value and are bulky and fibrous. In addition, these feed resources are also not well managed, especially where these are available in plenty. Availability of crop residues varies with season and region. In some regions there is deficiency of crop residues only in certain seasons, in others a perennial deficiency may prevail, while in some other regions and in particular seasons they 
are available in abundance but are largely wasted. Thus, straws worth millions of dollars are burnt in the fields in these places after the grain harvest. Apart from the wastage of a potential feed, the burning of straws causes environmental pollution and degradation of soil fertility. Improvement in the management of crop residues enables efficient utilization of this potentially useful feed resource.

So, in order to help and address the problem of small- scale farmers and develop it into a modern production sector strengthening the intermediate technology were essential.

\section{Objectives}

To adapt and evaluate the top hammer miller machine to crush crop residue for livestock feed purpose.

\section{MATERIAL AND METHODOLOGY}

\subsection{Experimental Site Description}

The experiment was conducted at Asella Agricultural Engineering Research Center (AAERC), Oromia Agricultural Research Institute (IQQO) located at $6^{\circ} 59^{\prime}$ to $8^{\circ} 49^{\prime} \mathrm{N}$ latitudes and $38^{\circ} 41^{\prime}$ to $40^{\circ} 44^{\prime}$ E longitudes, having an elevation of 2430 meters above sea level (masl), at Meki, which is located at latitude and longitude of $8^{\circ} 9^{\prime} \mathrm{N} 38^{\circ} 49^{\prime} \mathrm{E}$ with an elevation of 1636 meters above sea level and Bekoji which is located at latitude and longitude of $7^{\circ} 35^{\prime} \mathrm{N} 39^{\circ} 10^{\prime} \mathrm{E}$ with an elevation of $2810 \mathrm{~m}$.

\subsection{Description of the Machine}

Two top feed hammer mills, collected from market and Bako agricultural engineering research center (BAERC) were used and the major components of the top feed hammer millers machine are the frame, pulleys, hopper, sieve, and hammer and hammer house. Figure 1 show both machines used in the experiment.

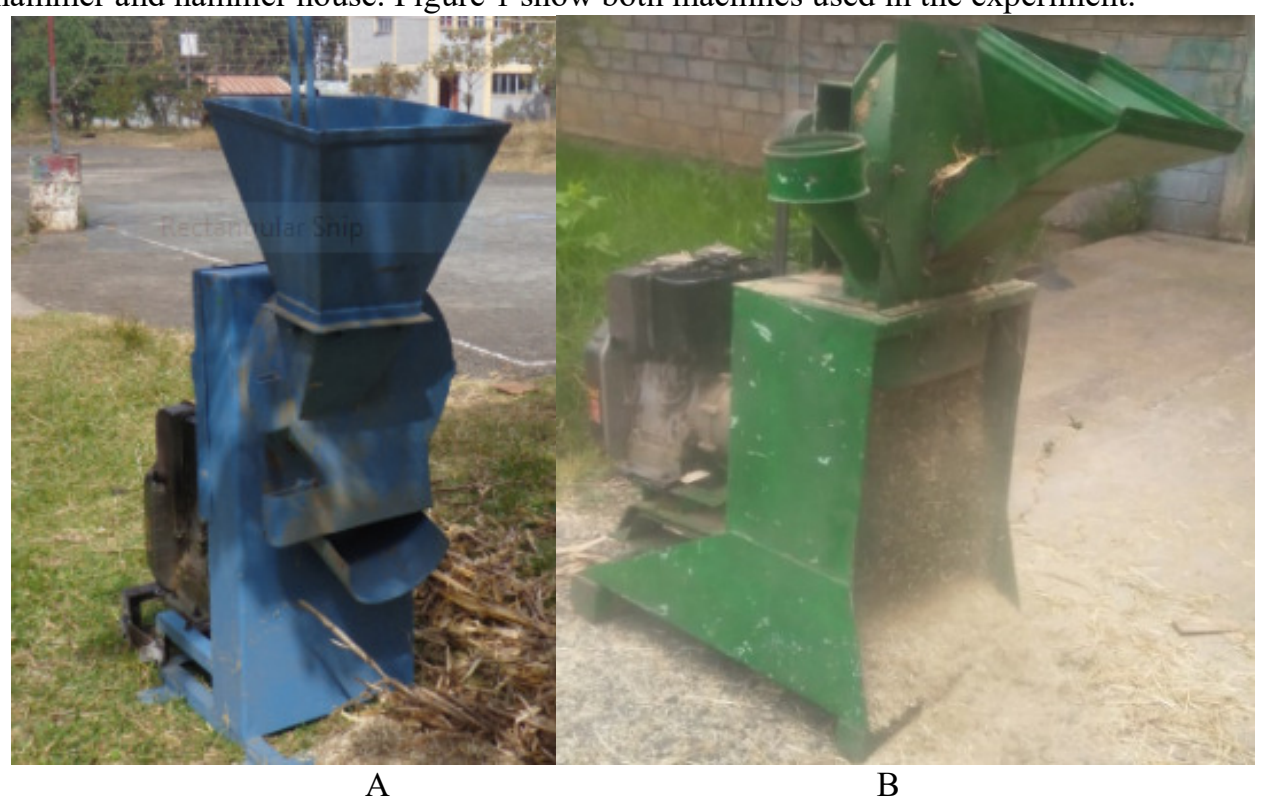

Figure 1. Machines used during experiment $(\mathrm{A}=\quad$ Machine from Market, $\mathrm{B}=$ machine from $\mathrm{BAERC})$

\subsection{Sieve size Determination}

Determination of the sieve hole size was done depends on the recommended particle size for different animals. According to the Egyptian standard specification for prepared animal feeds and feedstuffs, compressed feeds are sized into four categories a) sizes $<2 \mathrm{~mm}$ in diameter ranked: powder or mash, which was used for all types of poultry and birds. b) sizes $2-6 \mathrm{~mm}$ in diameter, which was used for rabbits, goats and fishes. c) Sizes 5-10mm in diameter for small animals ( $<6$ months). d) Sizes $10-22 \mathrm{~mm}$ in diameter for large animals ( $>6$ months) (Basiouny and Yamani, 2016).

\subsection{Modified Parts}

The modification was done on parts of market hammer. These parts are engine sit, sieve whole size, bearing frame. Originally the hammer miller is designed to mill grain so the sieve is too small to mill crop residue for animal feed purpose. Therefore sieve size is selected from 2 to 6,10 and $12 \mathrm{~mm}$ diameter accordingly. The Bearing frame changed from flat iron to angle iron due to repeatedly broken during high load.

2.5. Crushing Material The tested materials were maize stalk, bean straw, and wheat and barley straw after 
threshing.

\subsection{Working Principle}

A $12 \mathrm{hp} \mathrm{ACME} \mathrm{diesel} \mathrm{engine} \mathrm{was} \mathrm{used} \mathrm{as} \mathrm{source} \mathrm{of} \mathrm{power} \mathrm{to} \mathrm{operate} \mathrm{the} \mathrm{machine} \mathrm{during} \mathrm{the} \mathrm{entire} \mathrm{work} \mathrm{of} \mathrm{the}$ experimental investigation. The machine was adopted to employ a combination of hammering and sieving principles to crush and mill the crop residue. Crop residue was prepared and subjected to the hammer through the hopper with predetermined rate. Then the rotating hammer bit the crop residue in the hammer house until, it abled to pass through the sieve to the outlet. The hammer mill is conventionally a hammer-like projection mounted on a rotating shaft. The hammers are hung in such a way that they can swing either ways depending on centrifugal force or impact on the materials. The hammers revolve at high speed and crush the materials fed into its chamber by beating. Hammer size, number and arrangement are very important. Hammers are usually installed on high speed shafts. The distant between the screen and hammer should be 12 to $14 \mathrm{~mm}$ for size reduction of cereal grains and about $5 \mathrm{~mm}$ for fibrous material (HOQUE et al, 2007). But according this experiment the distance is fixed to $2.5 \mathrm{~cm}$.

\subsection{Measuring Devices and Instruments}

Cole-Parmer 8204 tachometer, with measuring range of 62 to $19999 \mathrm{rpm}$ and having a resolution of $1 \mathrm{rpm}$ was used to measure the speeds of shafts. SALTER Model $2356 \mathrm{~S}$ - digital spring balance, made in England capacity of $50 \mathrm{~kg}$ with $200 \mathrm{~g}$ difference, was used to measure weights of samples before and after crushing the experiments.

\subsection{Preparation of Samples}

Samples for experimental investigations were prepared from materials obtained after threshing of wheat and bean, and after harvesting of maize. Three kilogram of samples with three replications were taken, crushed and weighed to determine the mass of crushed materials before and after commencing on the experiment. The samples prepared were fed at the rate of $3 \mathrm{~kg}$ at predetermined hammer shaft speed (1200, 1800 and 2200RPM).

\subsection{Performance Evaluation}

During each test run materials inserted in the hopper and leaving through the outlet (mass before and after crushing) were weighted using digital balance Performance evaluation of the top hammer mill was made on the basis of crushing efficiency, crushing capacity, crushing loss and fuel consumption. As per Hesham et al., 2015 crushing efficiency and capacity as well as crushing losses were calculated using Eq. (1,2 and 3).

\section{Crushing efficiency (CE)}

$$
\mathrm{CE}=\frac{\text { Mass of materials after crushing }(\mathrm{kg})}{\text { mass of materials before crushing }(\mathrm{kg})} \times 100 \%
$$

2. Crushing capacity $(\mathbf{C C})$

$$
\mathrm{CC}=\frac{\text { total mass of materials crushing }(\mathrm{kg})}{\text { total time taken }(\mathrm{hr})}
$$

3. Crushing loses (CL)

$$
\begin{gathered}
\mathrm{CL}=\frac{M b-M a}{M b} x 100 \% \\
\text { Where } \mathrm{M}_{\mathrm{b}}=\text { mass before crushing }(\mathrm{kg}) \\
\mathrm{M}_{\mathrm{a}}=\text { mass after crushing }(\mathrm{kg})
\end{gathered}
$$

\subsection{Estimation of Fuel consumption}

Fuel consumption: to measure the fuel consumption, first top hammer mill kept on leveled surface. The fuel tank was filled up to top of the tank before the test started. After the completion of the crushing operation the engine was stopped and then the tank refilled to the original level. The quantity of fuel filled in the tank was measured using measuring cylinder and taken as actual fuel consumption.

\subsection{Statistical Analysis}

Data were subjected to analysis of variance following a procedure appropriate to the design of the experiment as recommended by Gomez and Gomez (1984). Analysis was made using statistix 8.0 statistical software. The treatment means that were different at $5 \%$ and $1 \%$ levels of significance were separated using LSDT. Level of significance $(\mathrm{P})$ for these relations was obtained by $\mathrm{F}$ - test based on analysis of variance.

\section{RESULT AND DISCUSION}

\subsection{Primary Testing}

The crusher defined as the machine or the tool which designed and manufactured to reduce the large materials into smaller chunks (Hesham etal, 2015). It could be considered as primary, secondary or fine crushers 
depending on the size reducing ratio. Crushers classified depending on the theory of the crushing acting as, Jaw crusher, conical crusher and impact crusher. The impact crusher type is widely used in agricultural applications, these crushers use the impact rather than the pressure to chuck and break the materials.

Both of the market and Bako Agricultural Engineering Research Center (BAERC) Top hammer miller were impact type crushers and fixed in the crushing of crop residues. The crushers have been feeding by different materials which were available in the test site. The feeding materials were, maize stalks, bean and wheat straws. The primary performance evaluation includes, crusher feed rate, productivity (output materials), and crushing and materials loss.

Each sample was weighted (mass before crushed) and passed through the feeding chute (hopper) into the crushing chamber, coming into contact with the pivoted hammers. The crushed materials were collected through the perforated screen below the crushed chamber. The time taken to crush each sample was recorded. The collected materials were weighted as mass after crushed. Each test replicated three times. The specific crushing resistance increases with the increase of the stalks fed through the chute.

Table1. Each top Hammer miller test results on different trial

\begin{tabular}{|l|l|l|l|l|l|l|l|}
\hline \multicolumn{1}{|c|}{} & \multicolumn{2}{|c|}{ BAERC Top hammer miller } & \multicolumn{3}{c|}{ Market top hammer miller } \\
\cline { 2 - 3 } & $\begin{array}{l}\text { Maize } \\
\text { stalk }\end{array}$ & $\begin{array}{l}\text { Bean } \\
\text { straw }\end{array}$ & Wheat straw & $\begin{array}{l}\text { Maize } \\
\text { stalk }\end{array}$ & Bean straw & $\begin{array}{l}\text { Wheat } \\
\text { straw }\end{array}$ \\
\hline Crushing efficiency (\%) & $98 \pm 1.9$ & $94 \pm 2$ & $97.33 \pm 4$ & $97.33 \pm 1.5$ & $99.33 \pm 1.6$ & $95 \pm 2.1$ \\
\hline Crushing capacity (kg/hr) & $\begin{array}{l}92.78 \pm \\
3\end{array}$ & $\begin{array}{l}78.68 \pm \\
2.5\end{array}$ & $109.75 \pm 2.6$ & $119.21 \pm 1.3$ & $152.54 \pm 2.2$ & $109.1 \pm 1.7$ \\
\hline Ave. Crushing loss (\%) & $2 \pm 0.1$ & $6 \pm 0.5$ & $2.67 \pm 0.37$ & $2.67 \pm 0.6$ & $0.67 \pm .02$ & $5 \pm 0.3$ \\
\hline \begin{tabular}{l|l|l|l|} 
Average Fuel consumed \\
for all stalk (lit/qut)
\end{tabular} & \multicolumn{3}{|c|}{0.35} & & 0.3 \\
\hline
\end{tabular}

From Table 1, it was observed that the market top crusher/ hammer machine give more crushing capacity, crushing efficiency than the BAERC top crusher/hammer machine and produced less crushing loss at different feed rate. Fuel consumption of top hammer mill machine was a little varies from crop to crop residue but not significant. As shown from Table 1 the average fuel consumption of Market and BAERC top hammer miller machines on all stalks for crushing of one quintal crop residue were 0.3 and 0.35 liter respectively.

\subsection{Effect of speed (rpm) on crushing capacity}

Nikolov (2004) stated a general scheme of crushing process as the impact breakage takes place in a very few time and results into a dynamic crack propagation that leads to much faster failure of particles at high speed. Increase in hammer shaft rpm, in general, lead to increasing crushing capacities on both BAERC and Market machines as shown in Figure 2. The mean values of crushing capacity were increased from 60 to $169 \mathrm{~kg} / \mathrm{hr}$ for BAERC and 74 to $189 \mathrm{~kg} / \mathrm{hr}$ for market top hammer mill machines respectively as rpm increase from 1200 to 2200 for all stalks on maize stalk. This was due to the fact that at higher hammers speed the crop residue forced to the crushed because of high inertia force acting on them.

\subsection{Combined Effect hammer Speed and Feed Rate on crushing efficiency, crushing capacity and crushing Loss}

Analysis of variance made in Table 2 indicates that the effect of feed rate was highly significant $(\mathrm{P}<0.01)$ on crushing capacity and crushing loss, and significant $(\mathrm{p}<0.05)$ on crushing efficiency.

Whereas, hammer speed $(\mathrm{RPM})$ was highly significant $(\mathrm{p}<0.01)$ on all crushing efficiency, crushing capacity and crushing loss. Feed rate and straw/stalk (FR x ST), hammer speed and Feed rate (RPM x FR) and straw/stalk and hammer (ST x RPM) combinations had highly significant $(\mathrm{P}<0.01)$ effect on both Crushing capacity and crushing loss except that ST $x$ RPM combination had significant effect at $\mathrm{P}<0.05$ on crushing efficiency. 
Table 2. Analysis of Variance Table for the result of the experiments

\begin{tabular}{lrccl} 
& & \multicolumn{2}{c}{ F-value } \\
\cline { 3 - 4 } source of variation & & $\begin{array}{l}\text { Crushing } \\
\text { Dfficiency }\end{array}$ & $\begin{array}{l}\text { Crushing } \\
\text { Capacity }\end{array}$ & $\begin{array}{l}\text { Crushing } \\
\text { Loss }\end{array}$ \\
\hline Replication & 2 & & & \\
FR & 2 & $1.7^{*}$ & $2.03^{* *}$ & $1.23^{*}$ \\
ST & 2 & 10.45 & $1.64^{*}$ & $9.61^{*}$ \\
RPM & 2 & $5.38^{* *}$ & $13.88^{* *}$ & $5.76^{* *}$ \\
ST*RPM & 4 & $3.06^{*}$ & $1.23^{* *}$ & $3.27^{* *}$ \\
FR*ST*RPM & 12 & $3.27^{* *}$ & $4.27^{* *}$ & $2.79^{* *}$ \\
Error & 26 & & & \\
\hline
\end{tabular}

$*, * *$; significant at 5\% and 1\% probability level, respectively; D.F degree of freedom

Crushing capacity and crushing loss were dominantly affected by feed rate and hammer speed (RPM) and followed by the type of stalk or straw. The interaction between Feed rate, type of straw/stalk and feed rate was highly significant on crushing efficiency, crushing loss and crushing capacity.

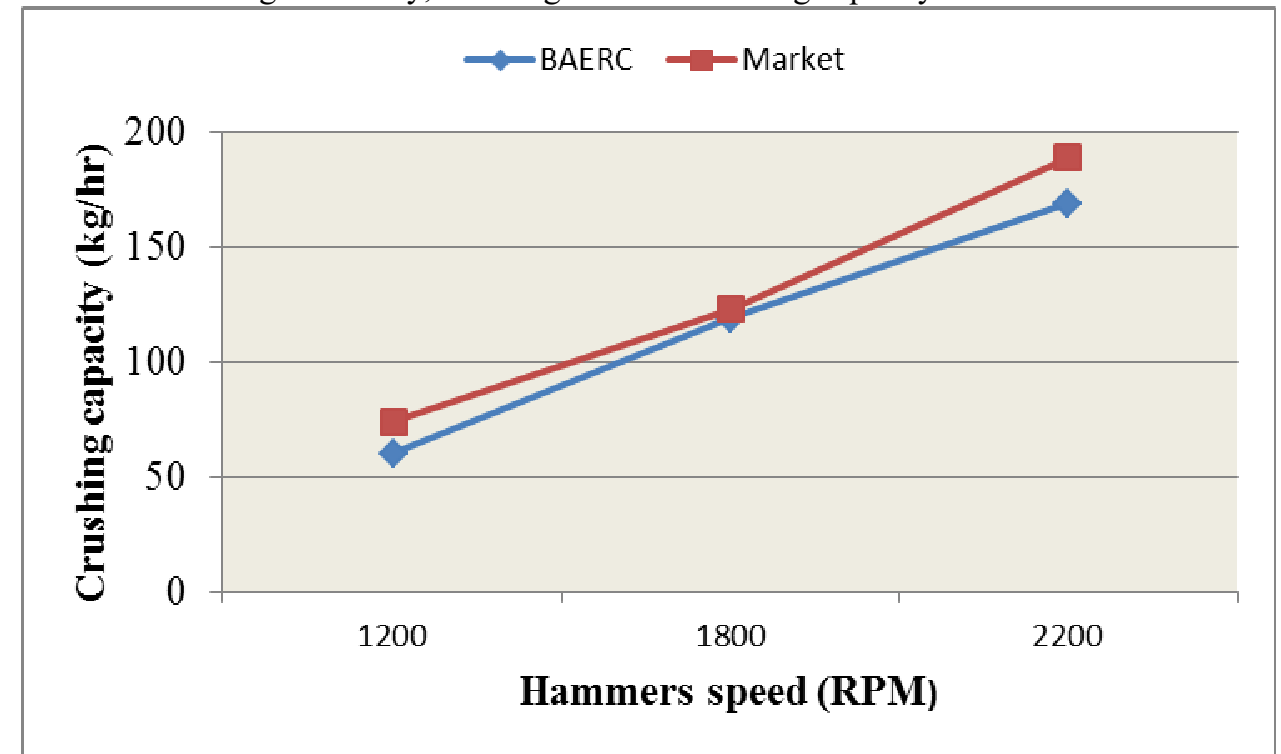

Figure 2. Effect of hammer's shaft speed on crushing capacity

\subsection{Effect of Hammer Speed on Crushing Efficiency and Crushing Loss}

As can be seen from Figure 3 increase in hammer shaft speed from 1200 to 1800 RPM increased crushing efficiency from 78 to $97 \%$; further increase in hammer shaft speed, to 2200 RPM, resulted in slightly decreasing crushing efficiency to $96 \%$ on maize stalk. The trend of graph is similar to all crop residues. The result obtained similar with Deepak (2008) stated that in an impact crusher the breakage take place in less time at high speed with slightly low efficiency.

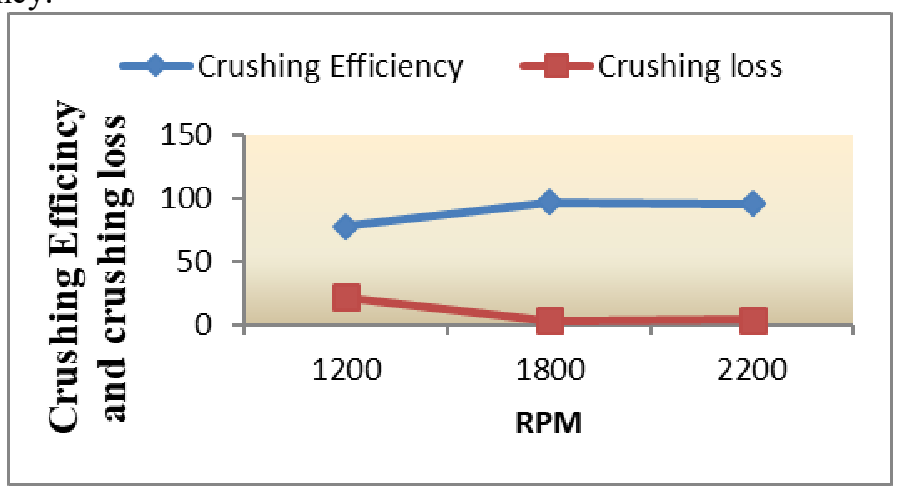

Figure3. Effect of rpm on crushing efficiency and crushing loss (maize)

The crushing loss decreased from 22 to $3 \%$ hammer shaft speed increase from 1200 to 1800 RPM. Nonetheless, the Crushing loss increased $4 \%$ as hammer shaft increased from 1800 to 2200 RPM as shown in Figure 3. 


\subsection{Cost Analysis of the Machine}

The cost of the machine includes raw material cost and production (machine and labor) cost only. Materials wastage and overhead costs are estimated from raw material and production cost.

Table 3. The summarized cost of the machine without engine

\begin{tabular}{|l|l|l|l|}
\hline No. & Variable & Cost (ETB) & \\
\cline { 3 - 4 } & & market & BAERC \\
\hline 1 & Raw material & 7560.63 & 9086.8 \\
\hline 2 & Materials Wastage $=2.5 \%$ of 1 & 189.02 & 227.17 \\
\hline 3 & Production (machine + labor) & 1354.33 & 2006.45 \\
\hline 4 & Overhead $=5 \%$ of 3 & 67.71 & 100.32 \\
\hline 5 & Profit $=10 \%$ of $(1+2+3+4)$ & 917.17 & 1142.1 \\
\hline 6 & Sell tax $=15 \%$ of $(1+2+3+4+5)$ & 1513.33 & 1884.43 \\
\hline 7 & Selling price $=(1+2+3+4+5+6)$ & 11602.19 & 14447.27 \\
\hline
\end{tabular}

\section{SUMMARY AND CONCLUSION}

Performance evaluations of the machines were done to determine crushing capacity, crushing efficiencies and associated losses at different speeds and constant feed rate. Three levels of hammer speed (1200, 1800 and 2200 rpm) were investigated to identify the optimum combination of the variables in question. The top hammer millers/crushers were subjected to test using available material such as Maize stalk, bean stalks and wheat straw with different hammer shaft speed.

Based on the performance evaluation made and results obtained, the following conclusions can be drawn

$>$ The outputs of the top hammer millers were satisfactory. The market top hammer miller produced a highest crushing efficiency and capacity about $99.33 \%$ and $152.54 \mathrm{~kg} / \mathrm{hr}$ while it was $94 \%$ and 78.68 $\mathrm{kg} / \mathrm{hr}$ when using the BAERC one respectively

$>$ The crushing losses the market top hammer miller were 2.67, 0.67 and $5 \%$ on maize stalk, bean stalk and wheat straw respectively.

$>$ Where BAERC top hammer were 2, $62.67 \%$ on maize stalk, bean stalk, wheat and barley straw respectively

$>$ It is recommended to use the Market one top hammer mill for it is better performance and simplicity, save the cost, easy of transportation and it is less in weight, simplicity in operation.

\section{RECCOMENDATION}

Based on the findings obtained, the following recommendations are made:

* Since the top hammers millers were originally designed for milling grain, the uniformity of feed materials (crop residue) into the crushing unit was not consistent; hence an automatic feeding or feeding table system and regulator must be developed and used instead of hopper,

* Lack of a variable electric or hydraulic motor made the use of diesel engine a must and control of speeds at different level was through reduction of engine speed, which was felt inappropriate; hence, further test, using power sources with digital variable speeds be made,

* The machine was tested and found satisfactory. However , a flywheel was attached to the hammer mill shaft to stop the lowering of the diesel engine speed noticed whenever much raw material was added to the chamber and

* Finally, It is decided that future commercialization shall been incorporating with feeding table system regulator and a flywheel at the hammer mill shaft.

\section{REFERENCE}

Basiouny, M. A. and A. E. El-Yamani, 2016. Performance Evaluation of Two Different Hammer Mills for Grinding Corn Cobs. J.Soil Sci. and Agric. Eng., Mansoura Univ., Vol. 7 (1):77- 87, 2016

Central Statistical Agency (CSA). 2013. Ethiopia Agricultural Sample Survey Addis Ababa. Volume III. Report On Livestock and Livestock Characteristics (Private Peasant Holdings). Federal Democratic Republic of Ethiopia

Central Statistical Agency (CSA) of the Federal Democratic Republic of Ethiopia 2015/16. Ethiopia Agricultural Sample Survey Addis Ababa. Volume II. Report On Livestock and Livestock Characteristics (Private Peasant Holdings).

Deepak, G. (2008). Design and analysis of a horizontal shaft impact crusher, thesis degree, National Institute of Technology (NIT), India.

FAO. 2012. Crop residue based densified total mixed ration - A user-friendly approach to utilise food crop byproducts for ruminant production, by T.K. Walli, M.R. Garg \& Harinder P.S. Makkar. FAO Animal 
Production and Health Paper No. 172. Rome, Italy.

Gomez, A.K. and A. A. Gomez. 1984. Statistical Procedures for Agricultural Research. John Wiley \& Sons. New York, USA.

Hesham, A., Yasser, M., Hanafi A. , Radwan and Tarek H., 2015. Redesign and Manufacture an Impact Crusher Hammer Mill Using Advanced Iron Casting. Global journal of advanced research. Vol-2, Issue-7 PP. 11961209

HOQUE M., SOKHANSANJ S., NAIMI L, BI X AND LIM J (2007). Review and Analysis of Performance and Productivity of Size Reduction Equipment for Fibrous Materials. ASABE paper no: 076164 St Joseph, Mich., pp2-6.

Nikolov, S. (2004). Modeling and simulation of particle breakage in impact crusher. International journal of mineral processing 74s: $219-225$.

Wiki love Africa, 2017. Agriculture in Ethiopia (Available at https://en.wikipedia.org/wiki/Agriculture_in_Ethiopia) 